\title{
US Sanctions against Iran; an Irreversible Disaster for Cancer Patients
}

\author{
Mohammadreza Barzegartahamtan, $\mathrm{MD}^{1,2^{*}}$; Seyed Rabi Mahdavi, $\mathrm{PhD}^{3}$; Peiman Haddad, $\mathrm{MD}^{4}$ \\ ${ }^{1}$ Clinical Research Development Unit, Loghman Hakim Hospital, Faculty of Medicine, Shahid Beheshti University of Medical Sciences, \\ Tehran, Iran \\ ${ }^{2}$ Radiation Biology Research Center, Iran University of Medical Sciences, Tehran, Iran \\ ${ }^{3}$ Radiation Biology Research Center, and Department of Medical Physics, Iran university of Medical Sciences, Tehran, Iran \\ ${ }^{4}$ Radiation Oncology Research Center, Tehran university of Medical Sciences, Tehran, Iran
}

A fter Joint Comprehensive Plan of Action (JCPOA) between Iran and 5+1 group countries, a relative space was opened to supply radiotherapy equipment in the country, ${ }^{1}$ which was suddenly disrupted by Trump's decision to leave JCPOA in May 2018 (Despite Iran's adherence to the agreement which has repeatedly been verified and approved by the International Atomic Energy Agency). The dollar and other currencies rose sharply and Iran's international trade with other countries was restricted. As a result, access to new equipment was hampered. Currently, repairing or supplying spare parts for accelerators are both expensive and time-consuming, resulting in prolonged device downtime. This means delays and/or interruptions in the course of patients' radiation treatment program and a decrease in the therapeutic effects of radiation as well as potential reduction of patients' survival. $^{2}$

In the case of brachytherapy utilizing radioactive sources, the situation is more deplorable. According to the ISRO (Iranian Society of Radiation Oncology) Survey in 2018, there were 18 brachytherapy centers including 8 remote after loading systems, 4 eye brachytherapy units, and 6 being in setup and/or inactive condition. However, lack of brachytherapy sources due to prior sanctions resulted in fact that only two centers have been used since 2015. ${ }^{3}$ Equipping the country's brachytherapy centers was improving after the JCPOA, but the trend has stopped again.

Advanced radiotherapy techniques, including IMRT, SRS, SBRT, etc., which nowadays constitute the majority of radiation treatments in developed and developing countries, are virtually absent in Iran. Iran's only Gammaknife center has been shut down due to lack of radioactive source. $^{3}$

The international medical community needs to take a practical action for this basic right of treatment as soon as possible.

\section{Authors' Contribution}

MRB and SRM wrote the manuscript and provided data. PE supervised the manuscript. All authors reviewed the final manuscript.

\section{Conflict of Interest Disclosures}

None.

Ethical Statement

Not applicable.

\section{References}

1. Kabolizadeh P, Aghili M, Balakhanlou B. A time for optimism? The state of radiation oncology in Iran. Int J Radiat Oncol Biol Phys. 2016;94(2):221-7. doi: 10.1016/j.ijrobp.2015.09.027.

2. Yazdi-Feyzabadi V, Amini-Rarani M, Delavari S. The Health Consequences of Economic Sanctions: Call for Health Diplomacy and International Collaboration. Arch Iran Med. 2020;23(4 Suppl1):S51-S53. doi: 10.34172/aim.2020. s11.

3. Ameri A, BarzegartahamtanM, Ghavamnasiri $M$, Mohammadpour R, Dehghan H, Sebzari A, et al. Current and future challenges of radiation oncology in Iran: a report from the Iranian society of clinical oncology. Clin Oncol (R Coll Radiol). 2018;30(4):262-268. doi: 10.1016/j. clon.2017.12.021. 